УДК 811. 161. 1

\title{
ПОВТОР КАК СРЕДСТВО МЕТАТЕКСТУАЛЬНОСТИ (НА МАТЕРИАЛЕ ОЧЕРКА М. ЦВЕТАЕВОЙ «МОЙ ПУШКИН»)
}

\author{
В.Ю. ШИШКІНА, К.О. ДУБІНА. ПОВТОР ЯК ЗАСІБ МЕТАТЕКСТУАЛЬНОСТІ (НА \\ МАТЕРІАЛІ НАРИСУ М. ЦВСТАСВОЇ «МІЙ ПУШКІН»). \\ У статті на матеріалі нарису Марини Цвєтаєвої «Мій Пушкін» розглядаються функиії
} повторів як одного із засобів метатекстуальності, яка визначається як властивість тексту, пов'язана з наявністю в ньому конструкиій, які використовуються автором для коментування, пояснення свого власного тексту з метою досягнення комунікативної мети, пов'язаної з адекватним сприйняттям тексту читачем відповідно до авторського задуму. Прагнучи в повному обсязі передати свої враження від знайомства в ранньому дитинстві зі спадщиною О.С. Пушкіна, Марина Цвєтаєва в нарисі максимально наближує стиль оповіді до емоиійного дитячого мовлення, щэо рясніс повторами. Відзначається, щэо повтори, які $\epsilon$ поліфункиіональними одинииями, можуть реалізовувати в тексті метатекстові функиії, основними з яких є наступні: коментування, уточнення, пояснення свого власного тексту, його структурування, відсилання до сказаного раніше, вербалізація когнітивної діяльності автора, розстановка акиентів, виділення головного і привертання уваги читача до найбільш важливого, $з$ позииії автора, фрагменту тексту. Метатекстові функиї можуть виконувати словотвірні (кореневі), лексичні і синтаксичні повтори. Досліджуються релевантні для реалізачї̈ метатекстових функиій структурні та семантичні особливості повторів, головними з яких є: лексичне наповнення, контактне або дистантне розташування повторюваних одиниць, повний або частковий (з урізанням, з ускладненням, варіативний) збіг повторюваних одиниць.

Ключові слова: метатекстуальність, метатекстові функиії, повтори, кореневі повтори, лексичні повтори, синтаксичні повтори.

В.Ю. ШИШКИНА, Е.А. ДУБИНА. ПОВТОР КАК СРЕДСТВО МЕТАТЕКСТУАЛЬНОСТИ (НА МАТЕРИАЛЕ ОЧЕРКА М. ЦВЕТАЕВОЙ «МОЙ ПУШКИН»).

В статье на материале очерка Марины Цветаевой «Мой Пушкин» рассматриваются функиии повторов как одного из средств метатекстуальности, которая определяется как свойство текста, связанное с наличием в нём конструкиий, которые используются автором для комментирования, пояснения своего собственного текста с иелью достижения коммуникативной цели, связанной с адекватным восприятием текста читателем в соответствии с авторским замыслом. Стремясь в полной мере передать свои впечатления от знакомства в раннем детстве с наследием А.С. Пушкина, Марина Цветаева в очерке максимально приближает стиль повествования к эмоциональной детской речи, изобилующей повторами. Отмечается, что повторы, будучи полифункииональными единицами, могут реализовывать в тексте метатекстовые функиии, основными из которых являются следуюшие: пояснение, уточнение, объяснение своего собственного текста, его структурирование, отсылка к сказанному ранее, вербализаџия когнитивной деятельности автора, расстановка акиентов, выделение главного и привлечение внимания читателя к наиболее существенному, с позиции автора, фрагменту текста. Метатекстовые функиии могут выполнять словообразовательные (корневые), лексические и синтаксические повторы. Исследуются релевантные для реализации метатекстовых функиий структурные и смысловые особенности повторов, главными из которых являются: лексическое наполнение, контактное или дистантное расположение повторяющихся единич друг по отношению к другу, полное или частичное (с усечением, с усложнением, вариативное) совпадение повторяющихся единиц.

Ключевые слова: метатекстуальность, метатекстовые функиии, повторы, корневые повторы, лексические повторы, синтаксические повторы.

(C) В.Ю. Шишкина, Е.А. Дубина, 2019

https://doi.org/10.34142/2312-1572.2019.01.67.10 
V.Y. SHYSHKINA, K.A. DUBINA. REPETITION AS A MEAN OF METATEXTUALITY (BASED ON TSVETAEVA'S ESSAY "MY PUSHKIN" MATERIAL).

The article based on Tsvetaeva's essay "My Pushkin" material considers functions of repetition as one of the means of metatextuality which is defined as a text characteristic related to the presence of structures in it that are used by the author for commenting, explaining his own text in order to achieve the communicative goal related to an adequate perception of the text by the reader in accordance with the author's intention. In order to fully convey her impressions of acquaintance the heritage of A.S. Pushkin in early childhood Marina Tsvetaeva in the essay makes the style of the narration as close as possible to the emotional children's speech abounding with repetition. It is noted that repetitions being polyfunctional units, along with others, can implement in the text metatext functions, the main of which are the following: clarification, elaboration, explanation of author's own text, its structuring, reference to foregoing, verbalization of the author's cognitive activity, arrangement of accents, highlighting the distillation and drawing the reader's attention to the most significant, in the author's view, fragment of the text. Metatext functions can perform word-formation (root), lexical and syntactic repetitions. The structural and semantic features of repetitions which are relevant to the implementation of metatext functions are studied, foremost among them are: lexical content, contact or distant arrangement of repeating units relative to each other, full or partial (with truncation, complication, variable) coincidence of repeating units.

Keywords: metatextuality, metatext functions, repetitions, root repetitions, lexical repetitions, syntactic repetitions.

Проблема метатекста как элемента структурной, семантической, прагматической организации текста и метатекстуальности как свойства текста рассматривалась еще в трудах А.А. Потебни, Р.О. Якобсона, М.М. Бахтина, Ю.М. Лотмана и других ученых. Работа А. Вежбицкой «Метатекст в тексте» [1] дала новый толчок к глубокому исследованию этой проблемы с разных точек зрения: теории текста, семантики, прагматики, дискурсивного анализа, когнитивистики и т.д. Несмотря на наличие большого количества работ, посвященных метатекстуальности (работы Ю.Д. Апресяна, Н.Д. Арутюновой, В.А. Лукина, М.В. Ляпон, Е.В. Падучевой, Н.П. Перфильевой, А.А. Шаймиева, Т.В. Шмелевой и других исследователей), в которых рассматриваются средства и способы выражения метатекстуальности, функции различных метатекстовых элементов, роль метатекста в организации дискурса, особенности взаимодействия текста и метатекста, остается ряд дискуссионных и неисследованных вопросов, в теории метатекстуальности отсутствует терминологическое единство. В данной статье мы не ставим перед собой цель проанализировать различные подходы к определению понятия «метатекст», укажем лишь, что вслед за большинством исследователей под метатекстом мы понимаем «...рефлексию говорящего по поводу собственного речевого поведения, которая может быть связана как с употреблением отдельно взятого слова, так и содержательным планом текста, его композиционным построением, смысловой структурой» [2, с. 52]. Таким образом, метатекстовые средства - это единицы, которые используются автором для комментирования, пояснения, уточнения, структурирования своего собственного текста с целью более адекватного его понимания адресатом. Учеными вслед за А. Вежбицкой, которая отметила, что «метатекстовые нити могут выполнять самые различные функции» [1, с. 421], исследовались разные единицы с точки зрения реализации этих функций. Мы в данной статье рассмотрим повторы как средства метатекстуальности.

Исследованию повторов (фонетических, лексических, семантических, словообразовательных, грамматических, синтаксических), их функции в организации структуры и семантики текста, роли в создании образных средств посвящены работы многих исследователей: Т.Н. Акимовой, И.В. Арнольд, М.Л. Гаспарова, Н.Т. Головкиной, Л.В. Зубовой, Е.А. Иванчиковой, Н.А. Кожевниковой, В.А. Кухаренко, Ю.М. Лотмана, Е.А. Скоробогатовой, О.Н. Шаповаловой, Р.О. Якобсона и многих других. Разработка этой проблемы проводилась в основном на материале поэтических текстов.

Целью настоящей статьи является исследование различных функций повторов как средства метатекстуальности на материале прозы, а именно в очерке Марины Цветаевой «Мой Пушкин», что до настоящего времени не получило достаточного освещения. При этом следует отметить, что на материале поэзии М. Цветаевой повторы в разных аспектах изучались в работах Ю.Е. Бочкаревой, Л.В. Зубовой, З.П. Куликовой, А.М. Надежкина, Е.А. Скоробогатовой, 
Е.В. Урядниковой и других ученых.

Жизнь и творчество Марины Ивановны Цветаевой изучает на протяжении многих десятилетий целая плеяда исследователей (Е.О. Айзенштейн, М.И. Белкина, Т.М. Геворкян, Ю.М. Каган, И.В. Кудрова, Ю.М. Лотман, А.А. Саакянц и многие другие), находя все новые и новые смыслы в текстах, до сих пор не теряющих своей актуальности.

Прозаические произведения М.И. Цветаевой, и в частности очерк «Мой Пушкин», интересны тем, что, с одной стороны, будучи поэтом, она в прозу привносит элемент поэтичности, с другой - в прозе отсутствует формальная организация стиха, что, в некоторой степени, дает автору больше свободы, в частности, свободы комментировать и уточнять свой собственный текст для достижения коммуникативной цели по адекватному его восприятию читателем в соответствии с авторским замыслом. Дополнительные замечания к собственному тексту, многочисленные примечания, которые вплетаются в канву повествования, исправления и уточнения по поводу только что сказанного являются яркой отличительной чертой очерка, который можно назвать поэтической прозой. Произведение это стало попыткой Марины Ивановны воспроизвести свои детские впечатления о «её Пушкине», о доме, об окружающих, это воспоминания о взрослении и о том, как в ее жизни появилась Поэзия. Уместными и удачными нам кажутся слова Даниила Данина в предисловии к очерку: «"Мой Пушкин" - рассказ Цветаевой о том, как начиналась Цветаева» [5, с. 5].

Писательница стремится максимально точно передать свои детские впечатления, а потому форма изложения, которую она выбирает, также зачастую близка речи ребенка, которой свойственны многочисленные уточнения, комментарии и повторы, когда ему хочется акцентировать внимание на каком-то особенно значимом моменте своего рассказа или сразу после сказанного исправить себя самого, объяснить свои слова. С этой целью, помимо других средств, поэтесса использует повторы.

В очерке «Мой Пушкин» «метатекстуальные нити», образованные повторами, чрезвычайно сложны и многообразны, чем объясняется трудность и некая условность анализа. Вопервых, каждый повтор - явление многофункциональное, и иногда бывает сложно выделить главную функцию, так как на метатекстуальные функции наслаиваются и другие. Во-вторых, трудность анализа связана с наличием в одном предложении (или текстовом фрагменте) большого количества различных повторов, что усложняет текст структурно, семантически, коммуникативно, эмоционально. В связи с этим, чтобы ярче продемонстрировать функцию конкретного повтора, в некоторых случаях мы приводим не целое предложение, а его фрагмент. Отдавая себе отчет в том, что каждый повтор, как правило, выполняет несколько функций, в исследовательских целях мы описываем ту метатекстовую функцию, которая, на наш взгляд, является доминирующей.

В очерке «Мой Пушкин» метатекстовую функцию выполняют лексические, синтаксические и в некоторых случаях словообразовательные корневые повторы. Трудно не согласиться с Н.Г. Петровой, которая считает, что «<...> для поэтов важен не столько повтор синтаксической конструкции, сколько ее лексическое наполнение» [3, с. 41], которое, зачастую, и дает возможность говорить о повторах как метатекстовых единицах. Кроме лексического наполнения для анализа метатекстовых функций повторов существенными, как показывает наш материал, являются следующие их особенности:

- контактное или дистантное расположение повторяющихся единиц друг по отношению к другу,

- характер повтора: полный (вторая повторяющаяся единица полностью совпадает с первой) или частичный, который может быть усеченным (во второй единице отсутствуют некоторые элементы первой), усложненным (вторая повторяющаяся единица имеет дополнительные элементы, отсутствующие в первой) и вариативным (вторая повторяющаяся единица по набору элементов не отличается от первой, но имеют место формальные отличия: порядок слов, морфологическая форма и т.д.).

Объем статьи не позволяет подробно остановиться на всех метатекстовых функциях повторов, остановимся на основных.

1. Функция пояснения, уточнения сказанного ранее проявляется в случаях частичного усложненного или вариативного повтора. Автор, назвав предмет, действие, признак, обстоятельство или ситуацию, повторяет эту же номинацию, дополнив необходимыми, на его взгляд, конкретизаторами, желая пояснить или уточнить сказанное для более успешной коммуникации. Так как грань между пояснением и уточнением при использовании повторов достаточно раз- 
мыта, мы в данной статье не разграничиваем эти понятия (это может быть предметом отдельного исследования), а термины используем как синонимичные. В этих случаях расположение повторяющихся элементов друг по отношению к другу не является релевантным признаком, так как независимо от того, контактно или дистантно расположены повторяющиеся единицы, уточнение сказанного достигается за счет дополнительных или измененных элементов.

Например, во фрагменте <... я я поделила мир на поэта - и всех, и выбрала - поэта, в подзащитные выбрала поэта: защищать поэта - от всех, как бы эти все ни одевались и ни назывались <...> автор с помощью контактно расположенного повтора, имеющего во втором элементе конкретизатор в подзащитные, уточняет цель действия, названного ранее, так как значение конструкции 'выбрать в + форма винительного падежа (неодушевленного)' близко к значению цели. Значение цели поясняется и во второй части конструкции использованием корневого повтора подзащитные - защищать. Кроме пояснения цели, употребление однокоренного глагола возвращает значение слова подзащитнные от более узкого, реализующегося в настоящее время для обозначения лица, защищаемого в суде адвокатом, к более широкому: 'находящийся под чвей-то защитой'.

Интересен с точки зрения метатекстуальной функции уточнения следующий фрагмент: "На печальные поляны льет печальный свет она..." О, господи, как печально, как дважды печально, как безысходно, безнадежно печально <..>, в котором М. Цветаева, используя тройной усложненный контактный повтор, где вторая и третья повторяющиеся единицы имеют дополнительные конкретизаторы, поясняет для читателя свое восприятие повтора у А.С. Пушкина. Сказав как печально, поэтесса понимает, что этого недостаточно для адекватной передачи ее эмоций после прочтения стихотворения, она уточняет: дважды печально, обращая внимание читателя на повтор прилагательных в приведенных ею (именно в приведенных ею, а не в оригинале) строчках А.С. Пушкина (печальные поляны и печальный свет). Но оказывается, что второй повтор также не дает полного представления о «качестве» печали (печаль у того же Пушкина может быть светла), тогда автор вводит третий повтор слова печально с наречиями безысходно, безнадежно, которые помогают точно выразить ощущения поэтессы, вызванные стихотворением «Зимняя дорога»: это всеобъемлющая, всеохватывающая печаль без конца и надежды на изменения.

Следует обратить внимание на то, что в тексте А.С. Пушкина, в отличие от приведенных М. Цветаевой строк с повтором двух прилагательных, имеет место корневой повтор прилагательного и наречия (На печальные поляны льет печально свет она...). Как представляется, именно в измененном виде этот фрагмент остался в памяти Марины Ивановны из детства, так как ее ощущению безысходной, всепоглощающей печали более соответствует по категориальным признакам полная форма прилагательного, которая передает постоянный признак. Для маленькой четырех-шестилетней Марины постоянство, неизменность состояния печали ассоциировалось с признаком предмета (в широком смысле), а не с признаком действия. Кроме этого, цветаевскому прочтению строк Пушкина способствуют непрямой порядок слов, если это наречие, и прямой (что для ребенка привычней), если это прилагательное, и наличие в тексте такого же прилагательного (печальные поляны), поэтому свет также печальный, т.е., имеет место, если так можно сказать, прогрессивная ассимиляция по частеречной принадлежности.

2. Функция структурирования текста, отсылки к сказанному ранее, указание направления движения мысли имеет место при использовании дистантно расположенных повторов. Это могут быть как полные, так и частичные повторы. Метатекстуальная функция в этом случае заключается в том, что, уводя читателя в сторону от основного повествования разного рода отступлениями, рассуждениями, попутными замечаниями, автор повтором возвращает его к сказанному ранее, к непосредственной теме повествования: Но до "Дуэли" Наумова - ибо у каждого воспоминанья есть свое до-воспоминание, предок - воспоминание, пращур - воспоминание, точно пожарная лестница, по которой спускаешься спиной, не зная, будет ли еще ступень которая всегда оказывается - или внезапное ночное небо, на котором открываешь все новые и новые высочайшие и далечайшие звезды - но до "Дуэли" Наумова был другой Пушкин, Пушкин, - когда я еще не знала, что Пушкин - Пушкин.

Основная канва повествования, заключенная в конструкции ...но до "Дуэли" Наумова был другой Пушкин..., разрывается достаточно большим по размеру, насыщенным по эмоциональной нагрузке, сложным по структуре и семантике рассуждением о воспоминаниях (где, в свою очередь, также используются повторы). И, чтобы вернуть читателя непосредственно к предмету повествования, автор использует повтор конструкции, находящейся до отступления. 
В отличие от типичных метатекстуальных средств структурирования текста и указания направления хода мысли (во-первых, во-вторых, далее, перейдем к ..., вернемся $к$... и подобные), использование повтора в этой функции не тормозит повествование, а делает его более напряженным, насыщенным эмоционально, нарушает линейность текста. Вместо указания читателю на необходимость вернуться к сказанному ранее (например, вернемся к ...), повтор возвращает его, одновременно напоминая о предмете речи.

3. Функция вербализации когнитивной деятельности автора проявляется в тех случаях, когда автор после определенных раздумий подтверждает или отрицает сказанное ранее, добавляя, как правило, слова или сочетания слов, за которыми стоит пресуппозиция 'я подумал/вспомнил и подтверждаю / отрицаю сказанное ранее’. Эту функцию могут выполнять любые типы повторов (полные и частичные, дистантные и контактные). Например, во фрагменте $\boldsymbol{C}$ тех пор, да, $\boldsymbol{c}$ тех пор, как Пушкина на моих глазах на картине Наумова - убили <...> между двумя контактно расположенными повторяющимися единицами находится слово $\partial a$, которое является сигналом метатекстуальной рефлексии автора после произнесения первой единицы. Автор на мгновение засомневался, действительно ли с тех пор, но после определенных раздумий приходит к выводу, что сказанное им вначале верно. За повтором с утвердительным (или отрицательным) элементом стоят последовательно следующие когнитивные процессы: сомнение, раздумье, окончательное решение и подтверждение (или отрицание) истинности сказанного.

При наличии отрицания автор как бы рассуждает вслух, объясняя после каждого повтоpa, в котором присутствует отрицание, причину, по которой он отказывается от только что сказанного. Например: Расизм до своего зарождения Пушкиным опрокинут в самую минуту его рождения. Но нет - раньше: в день бракосочетания сына арапа Петра Великого, Осипа Абрамовича Ганнибала с Марьей Алексеевной Пушкиной. Но нет, еще раньше: в неизвестный нам день и час, когда Петр впервые остановил на абиссинском мальчике Ибрагиме черный, светлый, весельй и страшный взгляд <...>.

Интересно отметить, что в подобных конструкциях, несмотря на то, что автор сам себя исправляет, отрицает сказанное ранее, считая, что нужно сказать иначе, он сохраняет в тексте и первоначальные, неверные, с его точки зрения, высказывания, желая, чтобы читатель следил за ходом его мысли, вместе с ним рассуждал и шел к нужному для автора выводу.

Эту же функцию, на наш взгляд, выполняют и корневые повторы, где повторяющиеся единицы могут относиться к разным частям речи, к одной части речи и могут быть формами одного слова. Отмеченная для поэтических текстов Е.А. Скоробогатовой особенность соположения однокоренных слов, заключающаяся в проявлении «<...> грамматических значений коррелятов на фоне семантического единства корней» [4, с. 54], как показывает материал, присуща и прозаическим текстам: $A x$, весь дом был тайный, весь дом был - тайна!. В этом примере соположение однокоренных прилагательного и существительного «<... участвует в создании значимого смыслового противоречия» [4, с. 55].

Значимым является и противопоставление форм слов: «C тех пор, да, с тех пор, как Пушкина на моих глазах на картине Наумова - убили, ежедневно, ежечасно, непрерывно убивали все мое младенчество, детство, юность <... . М. Цветаева противопоставляет формы совершенного и несовершенного вида, акцентируя внимание читателя на длительности, постоянстве, повторяемости действия: сколько раз маленькая Марина видела запечатленный на картине А.А. Наумова момент дуэли, столько раз на ее глазах поэта убивали. За повторами в таких конструкциях также стоят мыслительные процессы сомнения, раздумья, отрицания сказанного ранее, новая номинация, например, в предыдущем предложении: убили ..., нет, не убили, а убивали.

4. Функция выделения главного и привлечения внимания читателя к наиболее существенному, с позиции автора, фрагменту текста имеет место при контактном или дистантном, как правило, полном или вариативном повторе. При этом следует отметить, что эта функция присутствует в большинстве повторов, но не всегда является доминирующей, как в рассмотренных ниже примерах. Она наиболее ярко проявляется при расположении повтора в определенной позиции или в конструкциях определенной структуры.

А) Повторяющиеся единицы расположены дистантно и занимают сильные позиции в текстовом фрагменте:

- в начале предложений (не обязательно контактно расположенных): Чудная мысль Ибрагимова правнука сделать черным. <... Чудная мысль - чернотой изваяния дать Москве 
лоскут абиссинского неба. <...> Чудная мысль - наклоном головы, выступом ноги, снятой с головы и заведенной за спину шляпой поклона - дать Москве, под ногами поэта, море.

- в конце предложений (не обязательно контактно расположенных): ...Потому что мне нравилось, что уходим мы или приходим, а он - всегда стошт. Под снегом, под летящими листьями, в заре, в синеве, в мутном молоке зимь - всегда стоит.

Б) Повторяющиеся единицы расположены контактно, но во второй единице изменен порядок расположения элементов: Это я сейчас говорю, но знала уже тогда, тогда знала, а сейчас научилась говорить.

В) Повторяющиеся единицы вынесены в отдельное предложение: Море было здесь, $u$ завтра я его увижу. Здесь и завтра.

Г) В конструкциях с синтаксическим параллелизмом: Я ни тогда, ни потом, никогда не любила, когда целовались, всегда - когда расставались. Никогда не любила - когда садились, всегда - когда расходились.

Таким образом, повторы, наряду с другими средствами, могут выполнять в тексте метатекстуальную функцию, т.е. помогают автору расставить акценты, выделить главное, объяснить и уточнить свой собственный текст и достичь коммуникативной цели, связанной с адекватным восприятием текста читателем в соответствии с авторским замыслом. Стремясь в полной мере передать свои впечатления от знакомства в раннем детстве с наследием А.С. Пушкина, Марина Цветаева в очерке «Мой Пушкин» максимально приближает стиль повествования к эмоциональной детской речи, изобилующей повторами, основными метатекстовыми функциями которых являются следующие: пояснение и уточнение сказанного ранее, структурирование текста, отсылка к сказанному ранее, вербализация когнитивной деятельности автора, выделение главного и привлечение внимания читателя к наиболее существенному, с позиции автора, фрагменту текста.

\section{ЛИТЕРАТУРА}

1. Вежбицка А. Метатекст в тексте // Новое в зарубежной лингвистике. М : Прогресс, 1978. Вып. 8. С. 402-421.

2. Лукина Н. В. Метаобразования как средства диалогизации художественного текста (на материале произведений Т. Толстой) // Гуманитарные исследования. 2009. № 3 (31). С. 5154.

3. Петрова Н. Г. К вопросу о статусе лексического повтора в поэтическом дискурсе с позиций теории регулятивности // Вестник ТГПУ. Томск, 2010. Вып 6 (96). С. 39-44.

4. Скоробогатова Е. А. Грамматические значения и поэтические смыслы: поэтический потенциал русской грамматики (на материале категорий и лексико-грамматических разрядов имени). Харьков: НТМТ, 2012. 480 с.

5. Цветаева М. И. Мой Пушкин. Мой ответ Осипу Мандельштаму. Москва: ДиректМедиа, 2016. 87 с.

(Статья поступила в редакиџию 1 апреля 2019 г.) 
Русская филология. Вестник Харьковского национального педагогического университета имени Г.С. Сковороды. 2019, № 1 (67) 